\title{
Publisher's Erratum to: ISS Droplet Combustion Experiments - Uncertainties in Droplet Sizes and Burning Rates
}

\author{
Benjamin D. Shaw $\cdot$ Fei Yu
}

Published online: 1 August 2014

(C) Springer Science+Business Media Dordrecht 2014

Erratum to: Microgravity Sci. Technol.

DOI 10.1007/s12217-014-9377-x

Due to an oversight in production, the name and affiliation of the co-author, Fei Yu, were omitted in the original version of the article. The complete author list is shown above and their affiliation is given below. The publisher sincerely apologizes for this mistake.

The online version of the original article can be found at http://dx.doi.org/10.1007/s12217-014-9377-x.

B. D. Shaw $(\bowtie) \cdot$ F. Yu

University of California Davis, CA 95616, USA

e-mail: bdshaw@ucdavis.edu 